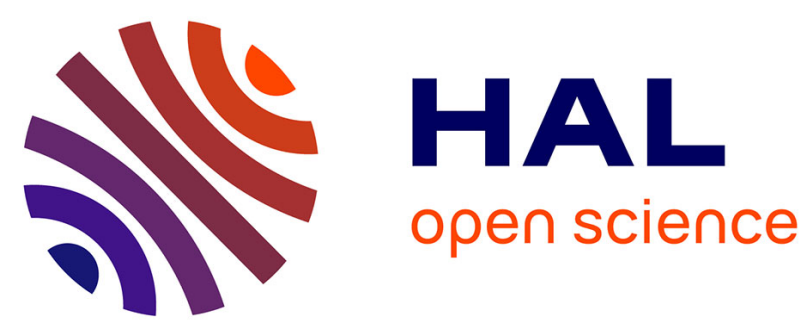

\title{
Estimation of fracture toughness of liver tissue: Experiments and validation
}

\author{
Can Gokgol, Cagatay Basdogan, Demircan Canadinc
}

\section{To cite this version:}

Can Gokgol, Cagatay Basdogan, Demircan Canadinc. Estimation of fracture toughness of liver tissue: Experiments and validation. Medical Engineering \& Physics, 2012, 34 (7), pp.882-891. 10.1016/j.medengphy.2011.09.030 . hal-03177362

\section{HAL Id: hal-03177362 \\ https://hal.science/hal-03177362}

Submitted on 23 Mar 2021

HAL is a multi-disciplinary open access archive for the deposit and dissemination of scientific research documents, whether they are published or not. The documents may come from teaching and research institutions in France or abroad, or from public or private research centers.
L'archive ouverte pluridisciplinaire $\mathbf{H A L}$, est destinée au dépôt et à la diffusion de documents scientifiques de niveau recherche, publiés ou non, émanant des établissements d'enseignement et de recherche français ou étrangers, des laboratoires publics ou privés. 


\title{
Estimation of Fracture Toughness of Liver Tissue: \\ Experiments and Validation
}

\author{
Can Gokgol, Cagatay Basdogan*, Demircan Canadinc \\ College of Engineering, Koc University,
}

Istanbul, 34450, Turkey

\begin{abstract}
In several medical procedures such as catheter insertion, robotic-guided needle placement, suturing, cutting or tearing, and biopsy, fracture toughness of the soft tissue being penetrated, cut, or teared plays a crucial role in force interactions between the surgical tool and the tissue. Although significant amount of experimental work carried out on hardbiomaterials, such as bone and dentin to estimate their fracture toughness, the number of studies on soft tissues is very limited and the estimated values show large variations. In this study, we show that the toughness values estimated in the earlier studies show large variations because the effect of puncturing/cutting tool geometry on the results has been mostly neglected. To prove our argument, needle insertion experiments are performed on 3 bovine livers with 4 custom-made needles having different diameters. A unique value for the fracture toughness of bovine liver is obtained by curve fitting to the toughness values estimated from the insertion experiments for different needle diameters $\left(\mathrm{J}=164 \pm 6 \mathrm{~J} / \mathrm{m}^{2}\right)$. In order to validate the experimental results, finite element (FE) simulations are performed. For this purpose, we

\footnotetext{
${ }^{*}$ Corresponding author:

College of Engineering

Koc University

Istanbul, 34450, Turkey

Tel: $90+212-338-1721$

Fax: 90+212-338-1548
}

e-mail: cbasdogan@ku.edu.tr
\end{abstract}


first collect experimental data from the bovine livers via static indentation and ramp and hold experiments to estimate their hyper-viscoelastic material properties through an inverse FE solution. Then, we simulate needle insertion into the FE model of each liver using the energybased fracture mechanics approach. The force responses obtained through the FE simulations for different needle diameters show an excellent agreement with the ones acquired through the physical experiments.

Keywords: Fracture toughness; needle insertion; hyperelasticity; viscoelasticity; finite element modeling.

\section{Introduction}

Significant advances are made in medical robotics, image-guided surgery, and computer-aided surgical planning and simulation during the last two decades. In all of those fields, accurate modeling of the interaction forces between surgical instruments and soft organ tissues is important for the proper execution or the simulation of a medical procedure. To estimate these forces accurately through a model, material properties of the soft organ tissues in which the surgical instruments interact must be known. While many of these properties have already been examined extensively, some are left unnoticed, such as fracture toughness, the resistance of a material to fracture. Only in a few exceptional works, the emphasis was placed on estimating the fracture toughness of a material [1-6], using the fracture toughness to study the geometrical effects of the instruments on penetration models [7], and measuring force response during needle penetration [8-10]. However, in several medical procedures such as catheter insertion, robotic-guided needle placement, biopsy, surgical suturing, and soft tissue cutting, fracture toughness of the organ being penetrated, punctured, or cut plays a crucial role in estimating the interaction forces between the surgical 
instrument and the organ. Specifically, all these procedures involve tissue damage up to a certain extent, which, however, should be kept to a minimum in order to avoid any medical complications [11-13]. Thus, the knowledge of fracture related material properties, especially the fracture toughness, is of utmost importance. Despite the significant amount of work carried out on hard-biomaterials, such as bone [14] and dentin [15], to determine their fracture toughness, the number of studies on soft tissues is very limited and the estimated toughness values show large variations [16]. The fracture mechanics approach based on the energy balance forms the basis of most of the existing studies [17]. Azar and Hayvard [1] inserted suture, syringe, and biopsy needles with diameters ranging from $0.71 \mathrm{~mm}$ to $2.1 \mathrm{~mm}$ into porcine liver to calculate the crack size and the fracture toughness of the liver. Two consecutive insertions were made into the same spot on the liver; the first one creating the crack and the second one being a free-pass. Then, the fracture toughness was calculated by dividing the difference between the fracture and the viscoelastic works to the crack area. The fracture toughness of the porcine liver was estimated to vary between 75.8 and $185.6 \mathrm{~J} / \mathrm{m}^{2}$. A scalpel was used by Chanthasopeephan et al. [2] as the cutting tool and the fracture toughness of pig liver was estimated to vary between 186.98 and $224.83 \mathrm{~J} / \mathrm{m}^{2}$, with a standard deviation reaching to $142 \mathrm{~J} / \mathrm{m}^{2}$ in some experiments. Cutting with scissors was considered by Pereira et al. [3] to estimate the fracture toughness of human skin. Skin samples were obtained from the hands of two cadavers and the fracture toughness for the dorsal skin was estimated as $1777 \pm 376 \mathrm{~J} / \mathrm{m}^{2}$ along the longitudinal direction and as $1719 \pm 674 \mathrm{~J} / \mathrm{m}^{2}$ along the circumferential direction and for the palmar skin as $2365 \pm 234$ $\mathrm{J} / \mathrm{m}^{2}$ along the skin creases and as $2616 \pm 395 \mathrm{~J} / \mathrm{m}^{2}$ across the skin creases. Comley and Fleck [4] estimated the toughness of porcine dermal and adipose skin tissue (soft connective tissue under the dermal layer) via a trouser tear test as $17000 \mathrm{~J} / \mathrm{m}^{2}$ and $4100 \mathrm{~J} / \mathrm{m}^{2}$, respectively. Misra et al. [5] used an experimental set-up to robotically steer Nitinol needles having 
different diameters and bevel tips into 3 different plastisol gels and a porcine gel. Using a single insertion, the rupture toughness of the plastisol gels in increasing stiffness, was estimated as $115.40,218.19$ and $221.04 \mathrm{~J} / \mathrm{m}^{2}$ respectively. The rupture toughness of the porcine gel was estimated as $82.28 \mathrm{~J} / \mathrm{m}^{2}$. Using a trouser tear test, Shergold [6] measured the fracture toughness of the silicone rubbers, grades Sil8800 and $\mathrm{B452}$, as $3100 \mathrm{~J} / \mathrm{m}^{2}$ and $3800 \mathrm{~J} / \mathrm{m}^{2}$, respectively. In an attempt to corroborate their penetration models for sharp-tipped and flat-bottomed punches [18], Shergold and Fleck [7] carried out penetration experiments on skin and skin-like silicone rubber. They investigated the effect of the punch-tip geometry on the mechanics of penetration using the experimental data obtained in [6].

The toughness values estimated in the earlier studies show large variations, partially due to the differences in the material properties of the subjects being tested and the methods being used for testing and evaluation. However, this issue has been left unattended, and no steps have been taken to improve the results. Although it is not uncommon for the material properties for different animals to show variation due to the individual differences, we hypothesize that part of this large variation in fracture toughness is due to the neglected effect of the puncturing/cutting tool geometry on the measurements. In particular, we point out that, even though the energy method has been used to evaluate the fracture toughness of soft tissues in the earlier needle insertion studies, no attention has been paid to the needle diameter in these evaluations. To prove our hypothesis, we perform needle insertion experiments on 3 bovine livers with 4 custom-made needles having different diameters and investigate the relation between the fracture toughness and the needle diameter. In order to validate the experimental results, FE simulations are performed in ANSYS. 


\section{Materials and Methods}

\subsection{Theory}

The insertion of a needle into a soft tissue can be investigated by dividing the process into multiple distinct phases $[8, \mathbf{1 6}, \mathbf{1 7}, \mathbf{1 9}, \mathbf{2 0}]$. The process starts with the deformation of the soft tissue under the force exerted by the needle (Fig. 1). Due to the viscoelastic nature of the soft tissue, this deformation continues until a certain threshold is reached in the relation between the viscoleastic work, $\mathrm{W}_{\mathrm{v}}$, and the fracture work, $\mathrm{W}_{\mathrm{f}}$. During the deformation phase, the value of $\mathrm{W}_{\mathrm{v}}$ starts out higher than the $\mathrm{W}_{\mathrm{f}}$. As the needle penetrates deeper into the soft tissue, the $\mathrm{W}_{\mathrm{f}}$ starts to increase and at some point, it becomes equal to the $\mathrm{W}_{\mathrm{v}}$. When the value of the $\mathrm{W}_{\mathrm{f}}$ surpasses the value of the $\mathrm{W}_{\mathrm{v}}$, the needle punctures the tissue and rupture occurs. This marks a very brief state change in the process of insertion; with the occurrence of rupture, the stage of pure deformation ends and a mixed stage of penetration and deformation starts (Fig. 1). At this stage, as the needle continues its movement through the soft tissue, the force values tend to increase until the needle comes to a full stop. A phase of relaxation begins, as the motion of the needle comes to an end and the soft tissue remains in this phase until the needle is extracted from the tissue.

In order to determine the fracture toughness, J, via the energy balance equation, a method involving two subsequent insertions of a needle into the same spot was suggested in $[8, \mathbf{1 7}]$. In the first insertion, all stages of insertion, namely deformation, rupture, and penetration, are present (Fig.1). As a result, the energy balance equation for the first insertion is:

$$
F_{1} d u=J d A+d \Delta+P d u
$$


where, $F_{1}$ is the force acting on the needle in the $1^{\text {st }}$ insertion and $\mathrm{d} u$ is the change in the needle displacement, and hence $F_{l} d u$ is the total work done by the needle during the first insertion, $P$ is the friction force and $P d u$ is the work done by friction. In Eq. 1, $\boldsymbol{d A}$ is the change in crack area (circumference of the needle times the incremental needle displacement, where the total crack area is the circumference times the current depth). With the assumption that friction in the system is accounted after the rupture occurs, the sum of $J d A$ and the friction work is equal to the fracture work, $\mathbf{W}_{\mathbf{f}}$; whereas, $d \Delta$, the change in the strain energy, is equal to the viscoelastic work, $W_{v}$. As a result, the total work becomes equal to the sum of $W_{f}$ and $W_{v}$.

In the second insertion to the same spot (Fig.1), which is a free pass, there is only the penetration stage, so the equation becomes:

$$
F_{2} d u=d \Delta+P d u
$$

where, $F_{2}$ is the force acting on the needle in the second insertion and smaller than $F_{1}$. As no rupture occurs in this insertion, the value of fracture work is equal to zero. Since, the change in strain energy, $d \Delta$, and the work done by friction, $P d u$ are exactly the same for both insertions, the subtraction of the Eq. (2) from the Eq. (1) results in:

$$
\left(F_{1}-F_{2}\right) d u=J d A
$$

If the left and right hand sides of the above equation are integrated with respect to $u$ and the lower and upper limits of the integral are taken as the start and the end of the penetration stage, the fracture toughness can obtained as: 


$$
J=\left(\int\left(F_{1}-F_{2}\right) d u\right) /\left(\int d A\right)
$$

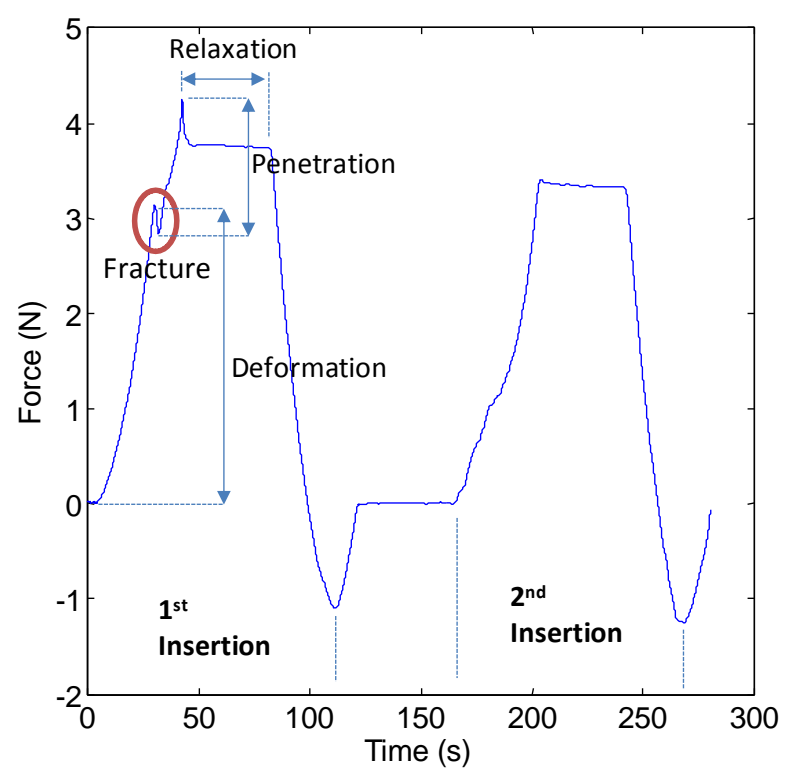

Figure 1. The phases of needle insertion into soft tissue.

\subsection{Experiments}

The experiments are carried out with fresh bovine livers harvested from 3 different animals (Fig. 2). No samples were taken from the livers; instead, the livers were used as a whole to minimize the blood loss and the changes in the boundary conditions. Extra caution was paid to collect data from the same lobe of each liver and avoid muscle tissue during the insertion. All experimental data is collected within 2 hours after harvesting.

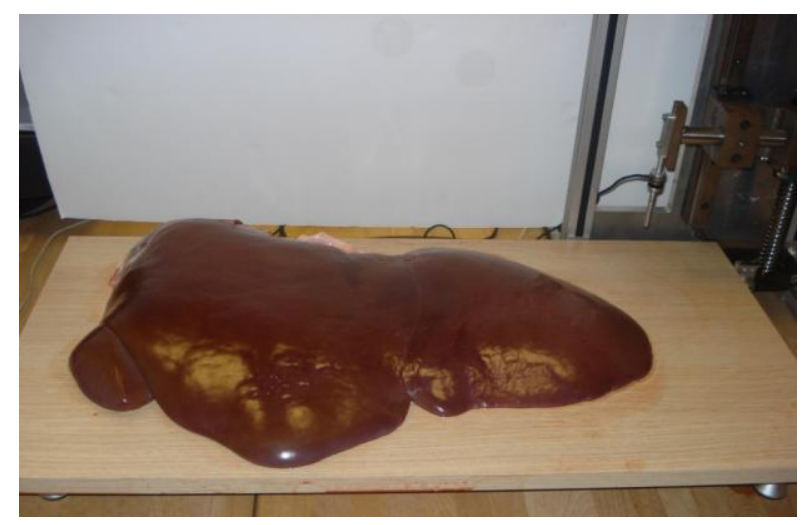

Figure 2. One of the 3 bovine livers used in the needle insertion experiments. 
An experimental set-up is developed to characterize the hyper-viscoelastic material properties of the bovine livers via a cylindrical compression probe first and then to make insertions into the same livers with 4 needles having different diameters to characterize their fracture toughness (Fig. 3). The major components of this set-up include a high-torque step motor moving the compression/insertion needle on a power screw and a force sensor attached to its shaft [21].

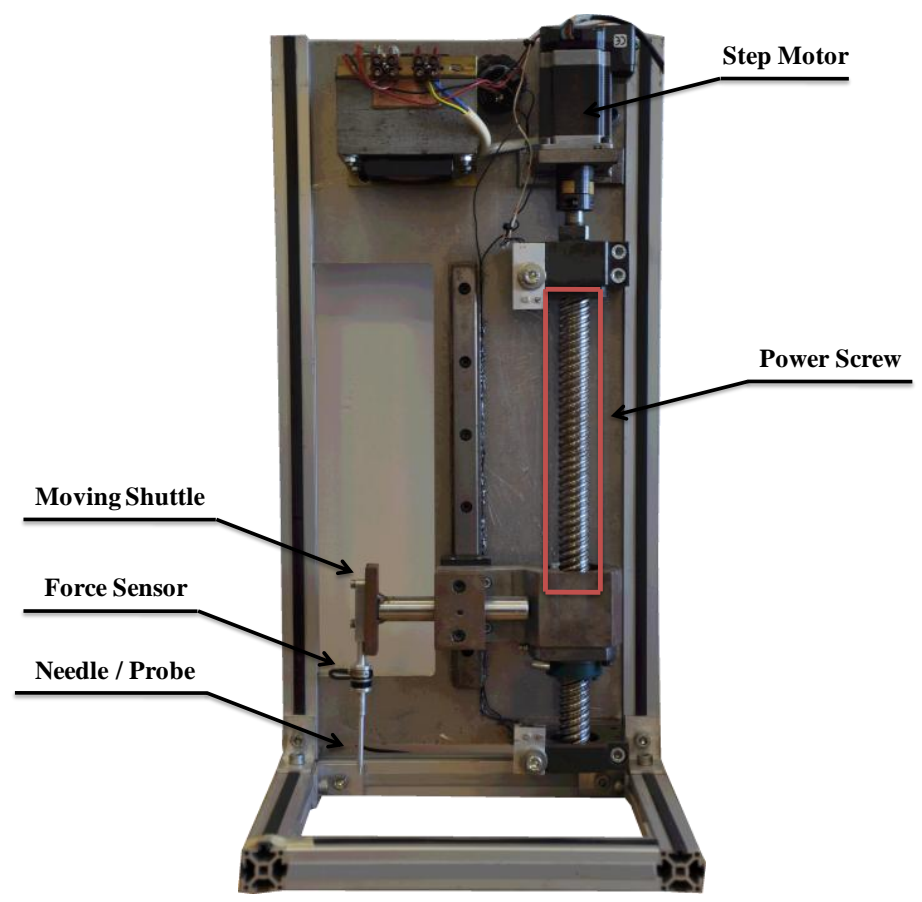

Figure 3. The set-up for conducting characterization and fracture toughness experiments.

In order to measure the strain-dependent hyperelastic response and time-dependent viscoelastic response, static indentation and ramp-and-hold experiments are performed on the livers respectively using a cylindrical probe having a round tip and a diameter of $6 \mathrm{~mm}$ (Fig. 4a). Then, to estimate the fracture toughness of the same livers, insertions experiments are performed using 4 different needles having sharp tips (Fig. 4a). The needle diameters are 2, 3, 4, and $5 \mathrm{~mm}$ and the entry angles are 12,18, 24 and 30 degrees respectively (as an example, the dimensions of the $2 \mathrm{~mm}$ needle are given in in Fig. 4b). 


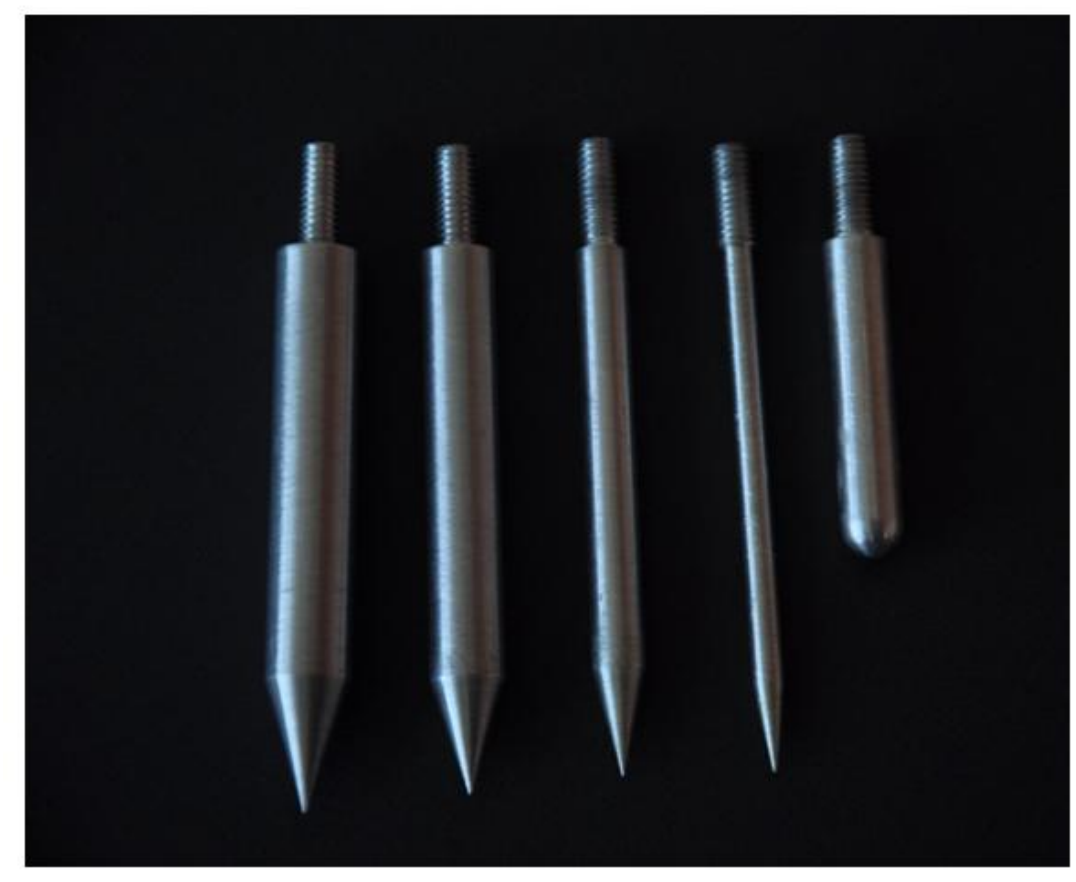

a)

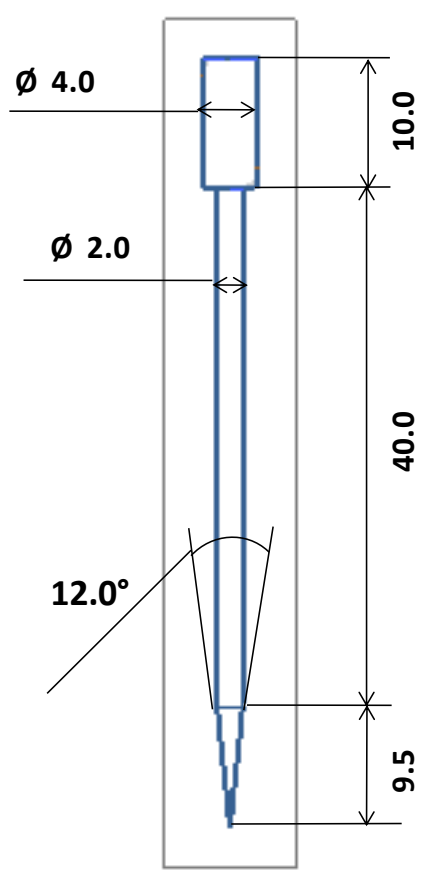

b)

Figure 4. The four needles used in the fracture toughness experiments and the cylindrical probe used in the characterization of hyper-viscoelastic material of bovine liver (a) and the technical drawing of the $2 \mathrm{~mm}$ needle (b).

\section{Results}

In static indentation experiments performed with the cylindrical probe, the liver samples are compressed to the depth of $20 \mathrm{~mm}$ with a rate of $0.5 \mathrm{~mm} / \mathrm{s}$ to eliminate the influence of viscoelastic and inertial effects, while the force response is measured by the force sensor (Fig. 5a). In ramp and hold experiments performed with the cylindrical probe, the livers are compressed to $20 \mathrm{~mm}$ in $1 \mathrm{~s}$ and the probe is held there for 125 seconds to record the force relaxation response as a function of time (Fig. 5b). 


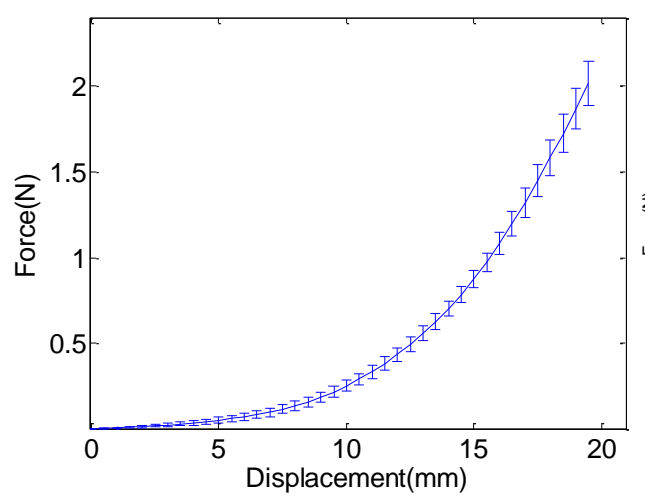

a)

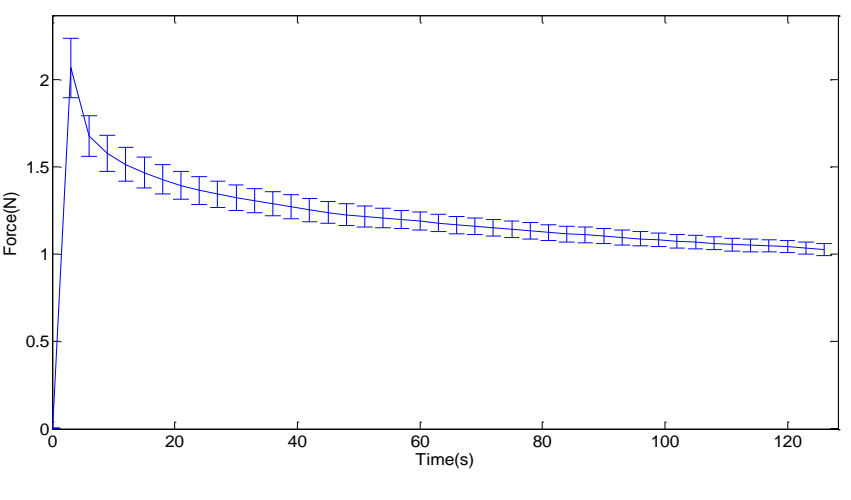

b)

Figure 5. The force response of bovine liver under static loading (a) and ramp and hold loading (b). The curves represent the averaged values of 3 animals and the bars show the standard deviations.

In order to estimate the fracture toughness of the bovine livers, each needle is penetrated into the depth of $20 \mathrm{~mm}$ with a rate of $3 \mathrm{~mm} / \mathrm{sec}$ and the force response is measured (Fig. 6). After a brief time of relaxation, the needle is retracted from the liver, only to be inserted once more into the same hole to measure the force response again. A total of four measurements are taken from the different sections of each liver and the insertion experiment is repeated for 4 different needles. Note that although the penetration depth is $20 \mathrm{~mm}$ in all measurements, the data is plotted up to the second rupture in Figs. $6 a, 6 b$ and $6 d$ in order to highlight the parallel nature of the curves after the initial rupture. 


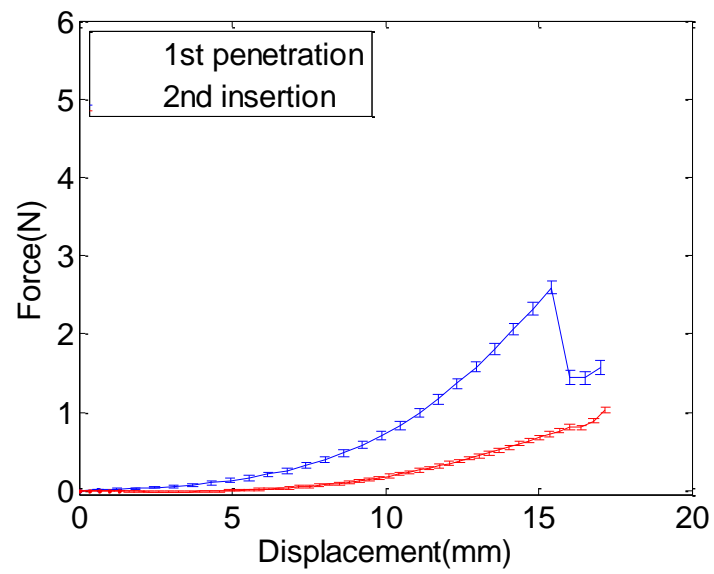

a

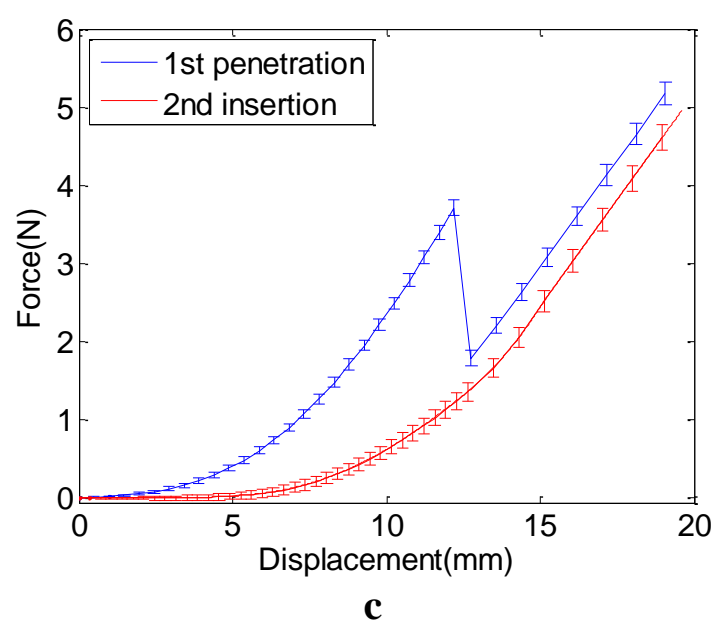

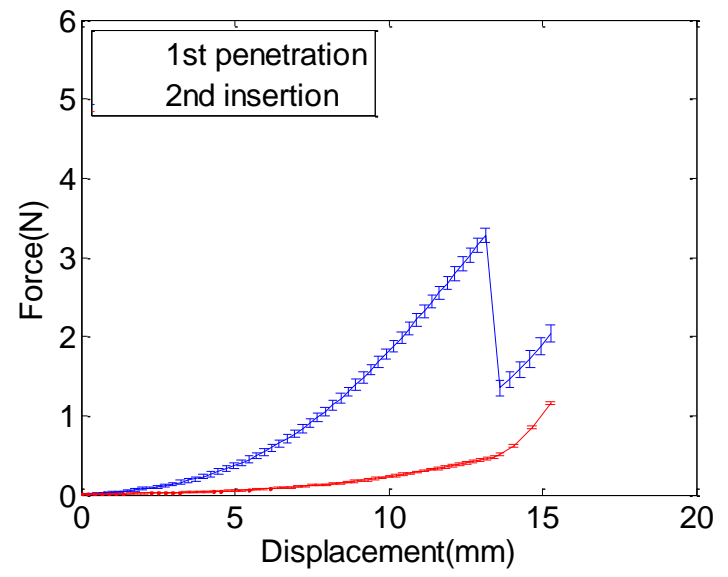

b

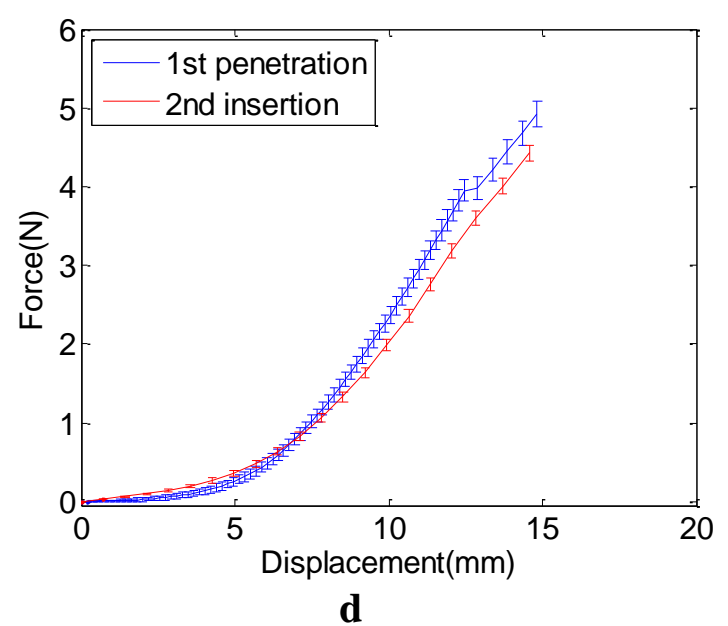

Figure 6. The force-displacement responses of the bovine liver of Animal \#1 for the needle diameters of $2 \mathrm{~mm}$ (a) $3 \mathrm{~mm}$ (b) $4 \mathrm{~mm}$ (c) and $5 \mathrm{~mm}$ (d). Each curve represents the average of 4 measurements performed on the liver and the bars show the standard deviations.

As shown in Fig. 6, the force curve of the first insertion is parallel to that of the second one after the initial rupture. The fracture toughness is estimated by integrating this difference over the needle displacement first and then dividing it by the crack area (Fig. 7). 


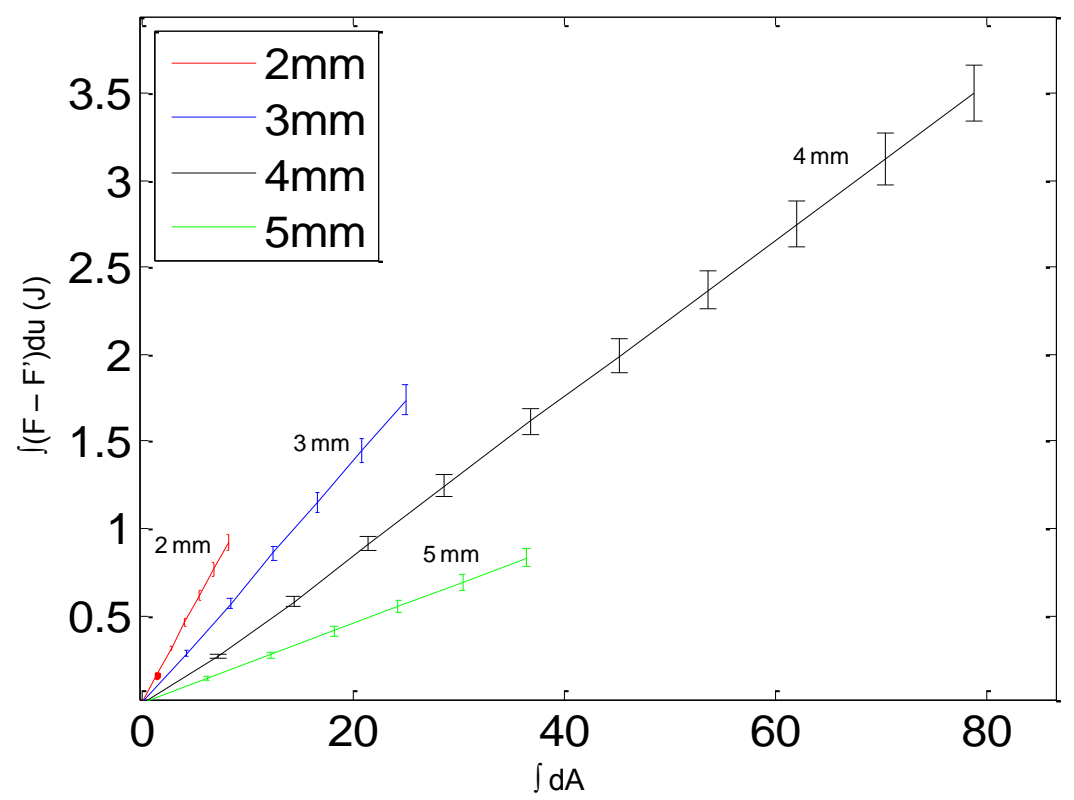

Figure 7. The relation between the fracture work and the crack area for different needle diameters. Each line is constructed based on the average of 4 measurements taken from the liver of Animal \#1 and the bars show the standard deviations.

The slope of each line in Fig. 7 returns the fracture toughness estimated for a particular needle diameter. As the needle diameter increases, the fracture toughness decreases (Tables 1 and 2). This is supported by the duration of the deformation stage in the force response curves shown in Fig. 6; as the needle diameter is increased, the duration of the deformation stage is decreased, indicating that the liver exerts less resistance to the larger needles. 
Table 1. The crack area $\left(\mathrm{mm}^{2}\right)$, the fracture toughness $\left(\mathrm{J} / \mathrm{m}^{2}\right)$, and the fracture work $\left(\mathrm{W}_{\mathrm{f}}\right)$ of the bovine livers for different needle diameters.

\begin{tabular}{|c|c|c|c|c|c|c|}
\hline \multirow[b]{2}{*}{ Animal No. } & \multirow[b]{2}{*}{$\begin{array}{l}\text { Needle } \\
\text { Diameter(mm) }\end{array}$} & \multirow[b]{2}{*}{ Parameters } & \multicolumn{4}{|c|}{ Test No. } \\
\hline & & & 1 & 2 & 3 & 4 \\
\hline \multirow{12}{*}{ Animal \#1 } & \multirow{3}{*}{$2 \mathrm{~mm}$} & dA $\left(\mathrm{mm}^{2}\right)$ & \multicolumn{4}{|c|}{$8.07 \pm 0.03$} \\
\hline & & $\mathbf{J}\left(\mathbf{J} / \mathbf{m}^{2}\right)$ & 120.3 & 107 & 113.5 & 116.55 \\
\hline & & $\mathbf{W}_{\mathbf{f}}(\mathbf{J})$ & 970.82 & 863.49 & 915.95 & 940.56 \\
\hline & \multirow{3}{*}{$3 \mathrm{~mm}$} & $\mathrm{dA}\left(\mathrm{mm}^{2}\right)$ & \multicolumn{4}{|c|}{$24.88 \pm 0.012$} \\
\hline & & $\mathbf{J}\left(\mathbf{J} / \mathbf{m}^{2}\right)$ & 73.85 & 69.32 & 65.62 & 70.85 \\
\hline & & $\mathbf{W}_{\mathrm{f}}(\mathbf{J})$ & 1837.4 & 1724.7 & 1632.6 & 1762.7 \\
\hline & \multirow{3}{*}{$4 \mathrm{~mm}$} & dA $\left(\mathrm{mm}^{2}\right)$ & \multicolumn{4}{|c|}{$78.74 \pm 0.053$} \\
\hline & & $\mathbf{J}\left(\mathbf{J} / \mathbf{m}^{2}\right)$ & 46.94 & 41.98 & 43.92 & 45.21 \\
\hline & & $\mathbf{W}_{\mathrm{f}}(\mathbf{J})$ & 3656.7 & 3352.0 & 3374.8 & 3638.6 \\
\hline & \multirow{3}{*}{$5 \mathrm{~mm}$} & $\mathrm{dA}\left(\mathrm{mm}^{2}\right)$ & \multicolumn{4}{|c|}{$36.35 \pm 0.043$} \\
\hline & & $\mathbf{J}\left(\mathbf{J} / \mathbf{m}^{2}\right)$ & 24.79 & 21.49 & 22.23 & 22.89 \\
\hline & & $\mathbf{W}_{\mathbf{f}}(\mathbf{J})$ & 901.11 & 781.16 & 808.06 & 832.05 \\
\hline \multirow{12}{*}{ Animal \#2 } & \multirow{3}{*}{$2 \mathrm{~mm}$} & $\mathrm{dA}\left(\mathrm{mm}^{2}\right)$ & \multicolumn{4}{|c|}{$10.28 \pm 0.23$} \\
\hline & & $\mathbf{J}\left(\mathbf{J} / \mathbf{m}^{2}\right)$ & 114.78 & 110.12 & 107.57 & 108.37 \\
\hline & & $\mathbf{W}_{\mathrm{f}}(\mathbf{J})$ & 1179.9 & 1132.0 & 1105.8 & 1114.0 \\
\hline & \multirow{3}{*}{$3 \mathrm{~mm}$} & dA $\left(\mathrm{mm}^{2}\right)$ & \multicolumn{4}{|c|}{$19.42 \pm 0.14$} \\
\hline & & $\mathbf{J}\left(\mathbf{J} / \mathbf{m}^{2}\right)$ & 77.54 & 73.97 & 67.35 & 67.2 \\
\hline & & $\mathbf{W}_{\mathbf{f}}(\mathbf{J})$ & 1505.8 & 1436.5 & 1307.9 & 1305.0 \\
\hline & \multirow{3}{*}{$4 \mathrm{~mm}$} & $\mathrm{dA}\left(\mathrm{mm}^{2}\right)$ & \multicolumn{4}{|c|}{$54.39 \pm 0.041$} \\
\hline & & $\mathbf{J}\left(\mathbf{J} / \mathbf{m}^{2}\right)$ & 51.52 & 44.62 & 49.88 & 46.66 \\
\hline & & $\mathbf{W}_{\mathbf{f}}(J)$ & 2802.2 & 2426.9 & 2713.0 & 2537.8 \\
\hline & \multirow{3}{*}{$5 \mathrm{~mm}$} & dA $\left(\mathrm{mm}^{2}\right)$ & \multicolumn{4}{|c|}{$33.21 \pm 0.039$} \\
\hline & & $\mathbf{J}\left(\mathbf{J} / \mathbf{m}^{2}\right)$ & 23.75 & 20.18 & 21.06 & 19.01 \\
\hline & & $\mathbf{W}_{\mathbf{f}}(\mathbf{J})$ & 788.74 & 670.18 & 699.4 & 631.32 \\
\hline \multirow{12}{*}{ Animal \#3 } & \multirow{3}{*}{$2 \mathrm{~mm}$} & dA $\left(\mathrm{mm}^{2}\right)$ & \multicolumn{4}{|c|}{$11.42 \pm 0.27$} \\
\hline & & $\mathbf{J}\left(\mathbf{J} / \mathbf{m}^{2}\right)$ & 112.42 & 103.77 & 105.23 & 110.43 \\
\hline & & $\mathbf{W}_{\mathbf{f}}(\mathbf{J})$ & 1283.8 & 1185.1 & 1201.7 & 1261.1 \\
\hline & \multirow{3}{*}{$3 \mathrm{~mm}$} & $\mathrm{dA}\left(\mathrm{mm}^{2}\right)$ & \multicolumn{4}{|c|}{$25.94 \pm 0.38$} \\
\hline & & $\mathbf{J}\left(\mathbf{J} / \mathbf{m}^{2}\right)$ & 71.94 & 68.1 & 65.89 & 75.99 \\
\hline & & $\mathbf{W}_{\mathbf{f}}(\mathbf{J})$ & 1866.1 & 1767.6 & 1709.2 & 1971.2 \\
\hline & & $\mathrm{dA}\left(\mathrm{mm}^{2}\right)$ & & 57. & .02 & \\
\hline & $4 \mathrm{~mm}$ & $\mathbf{J}\left(\mathbf{J} / \mathbf{m}^{2}\right)$ & 50.21 & 45.27 & 41.44 & 42.94 \\
\hline & & $\mathbf{W}_{\mathbf{f}}(\mathbf{J})$ & 2880.6 & 2597.1 & 2377.4 & 2463.5 \\
\hline & & $\mathrm{dA}\left(\mathrm{mm}^{2}\right)$ & & 38. & .44 & \\
\hline & $5 \mathrm{~mm}$ & $\mathbf{J}\left(\mathbf{J} / \mathbf{m}^{2}\right)$ & 22.85 & 16.25 & 19.82 & 21.72 \\
\hline & & $\mathbf{W}_{\mathrm{f}}(\mathbf{J})$ & 889.78 & 632.78 & 771.79 & 845.78 \\
\hline
\end{tabular}


Table 2. The average fracture toughness $\left(\mathrm{J} / \mathrm{m}^{2}\right)$ of the bovine livers for different needle diameters.

\begin{tabular}{|l|c|c|c|c|}
\hline Needle Diameter & Animal \#1 & Animal \#2 & Animal \#3 & Average \\
\hline $\mathbf{2} \mathbf{~ m m}$ & $114.34 \pm 5.62$ & $110.21 \pm 3.23$ & $107.96 \pm 4.12$ & $110.83 \pm 4.32$ \\
\hline $\mathbf{3} \mathbf{~ m m}$ & $69.91 \pm 3.42$ & $71.52 \pm 5.11$ & $70.48 \pm 4.44$ & $70.63 \pm 4.32$ \\
\hline $\mathbf{4 ~} \mathbf{~ m m}$ & $44.52 \pm 2.09$ & $48.17 \pm 3.11$ & $44.97 \pm 3.32$ & $45.88 \pm 2.83$ \\
\hline $\mathbf{5} \mathbf{~ m m}$ & $22.85 \pm 1.41$ & $21.00 \pm 2.01$ & $20.16 \pm 2.89$ & $22.33 \pm 2.10$ \\
\hline
\end{tabular}

The data presented in both Tables 1 and 2 suggests that the fracture toughness is a linear function of needle diameter. An excellent agreement is obtained $\left(y=-29 x+164, R^{2}=\right.$ 0.981) when the average values of the fracture toughness for 3 animals are plotted against the needle diameter (Fig. 8). Using the y-intercept of the fit line, the fracture toughness of bovine liver is estimated as $164 \pm 6 \mathrm{~J} / \mathrm{m}^{2}$.

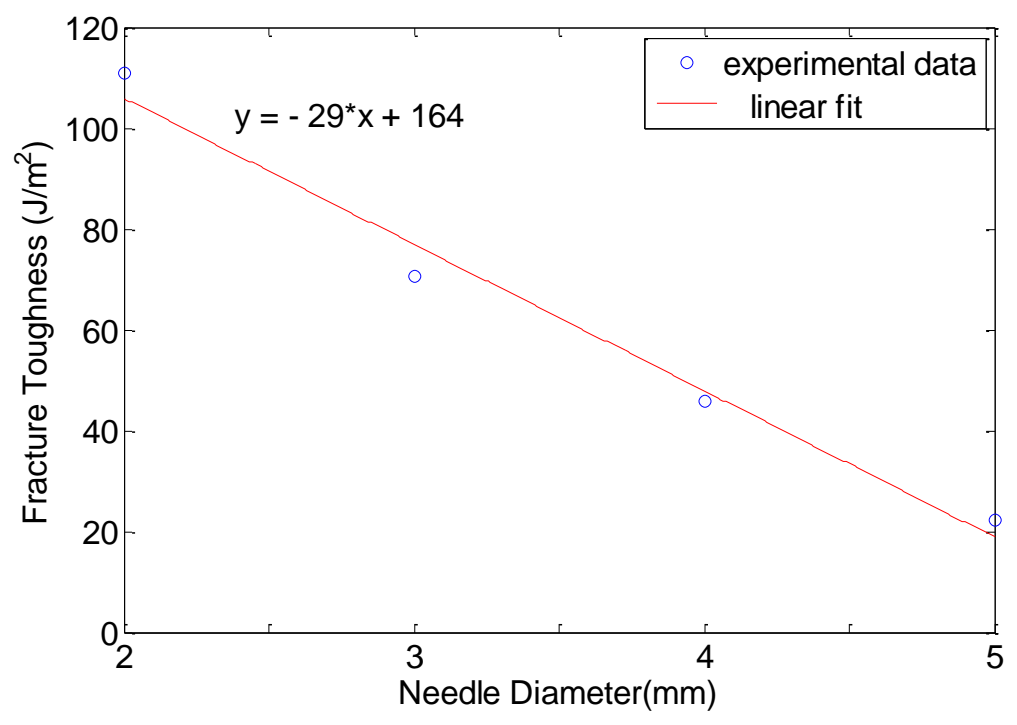

Figure 8. The fracture toughness of bovine liver as a function of needle diameter. Each data point on the plot represents the averaged values of 3 animals.

\section{Validation}


In order to validate the experimental results, a FE model of bovine liver is developed in ANSYS and the insertion experiments are simulated for each liver to compare the force response estimated by the FE simulations with the one obtained through the experiments. To reduce the computational load in FE simulations, a two-dimensional FE model is preferred over a three-dimensional one, only the area around the contact is considered for the FE analysis, and the solution is assumed to be symmetric with respect to the axis of loading (Fig. 9). The base of the FE model is constrained to have zero displacement. The coefficient of friction between the contacting surfaces is set to 0.8. The contact stiffness (FKN) and penetration tolerance (FTOLN) are set to 0.71 and 0.1 , respectively. These parameters are determined by trial and error using the guidelines given in ANSYS manual such that the simulations have converged to a feasible solution while no problems in contact and distortion in the elements are observed during the simulations.

After constructing the FE model, the hyper-viscoelastic material properties of each liver are determined by an inverse solution such that the total error between the experimental force response and the simulated one is minimized through a set of optimization iterations as suggested in [22]. Note that since the experiments are performed with a cylindrical probe on a whole liver, it is not possible to obtain the material properties directly from the measurements.

The Mooney-Rivlin strain energy function having 5-terms is used to model the hyperelastic behavior of each liver, which is defined as

$$
\begin{aligned}
W_{M R 5}= & C_{10}\left(I_{1}-3\right)+C_{01}\left(I_{2}-3\right)+C_{20}\left(I_{1}-3\right)^{2} \\
& +C_{11}\left(I_{1}-3\right)\left(I_{2}-3\right)+C_{02}\left(I_{2}-3\right)^{2}
\end{aligned}
$$

where, $\mathrm{C}_{10}, \mathrm{C}_{01}, \mathrm{C}_{20}, \mathrm{C}_{11}, \mathrm{C}_{02}$ are the hyperelastic material coefficients, $I_{1}$ and $I_{2}$ are the principle invariants. To be consistent with the experiments, the FE model of each liver is compressed to $20 \mathrm{~mm}$ by increments of $0.5 \mathrm{~mm} / \mathrm{step}$ (Fig. 9a) and the hyperelastic material 
coefficients are optimized by the inverse solution (Table 3 ). The solution is iterated until the magnitude of the total error between the force response obtained through the compression experiments and the one obtained through simulations is less than $0.05 \mathrm{~N}$ (Fig. 10a).

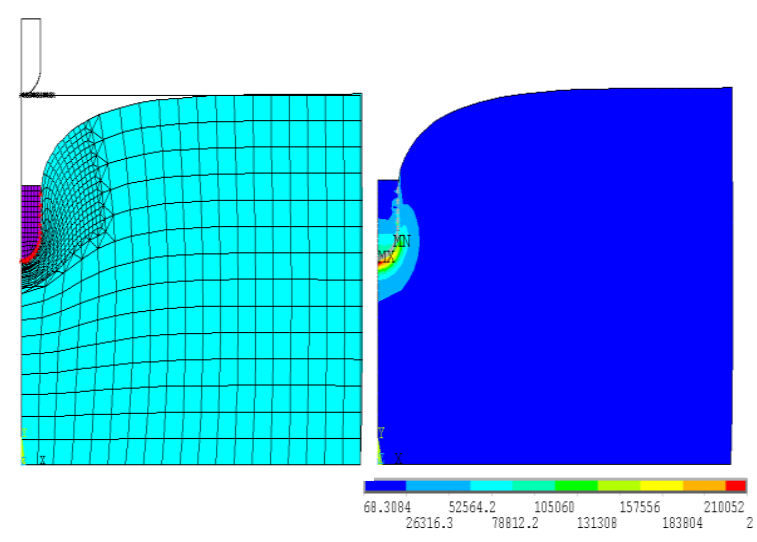

a)

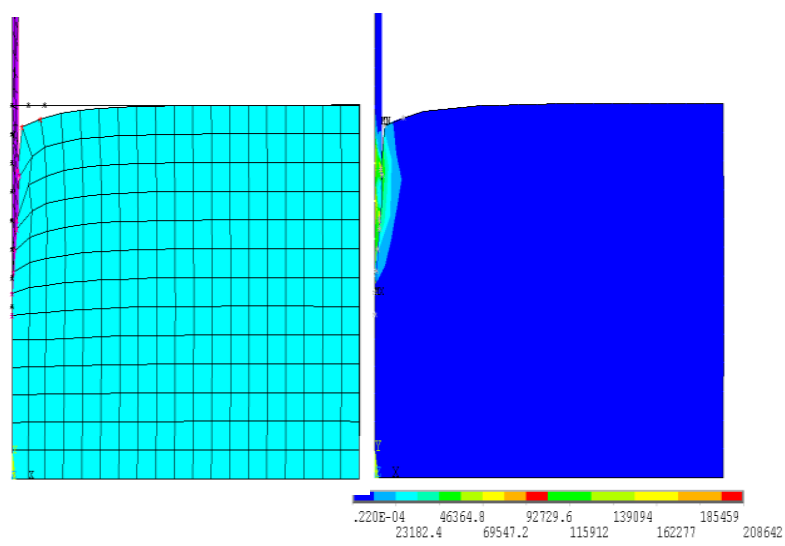

b)

Figure 9. The FE model of bovine liver deformed by the cylindrical probe having a round tip (a) and punctured by a needle having a sharp tip (b). The distribution of the Von-Misses stress around the probe/needle forms intertwined circles.

Table 3. The hyper-viscoelastic material coefficients of the bovine livers estimated through the inverse FE solution.

\begin{tabular}{|l|c|c|c|c|c|c|c|c|c|}
\hline Animal & $\mathbf{C}_{\mathbf{1 0}}$ & $\mathbf{C}_{\mathbf{0 1}}$ & $\mathbf{C}_{\mathbf{2 0}}$ & $\mathbf{C}_{\mathbf{1 1}}$ & $\mathbf{C}_{\mathbf{0 2}}$ & $\boldsymbol{\alpha}_{\mathbf{1}}$ & $\boldsymbol{\alpha}_{\mathbf{2}}$ & $\boldsymbol{\tau}_{\boldsymbol{1}}$ & $\boldsymbol{\tau}_{\mathbf{2}}$ \\
\hline$\# 1$ & 417.31 & 417.09 & 419.98 & 418.68 & 556.29 & 0.278 & 0.296 & 1.162 & 8.126 \\
\hline$\# 2$ & 456.40 & 416.24 & 417.82 & 418.24 & 716.83 & 0.351 & 0.278 & 0.978 & 10.573 \\
\hline$\# 3$ & 416.28 & 447.92 & 416.62 & 416.81 & 735.34 & 0.554 & 0.123 & 4.213 & 11.234 \\
\hline
\end{tabular}




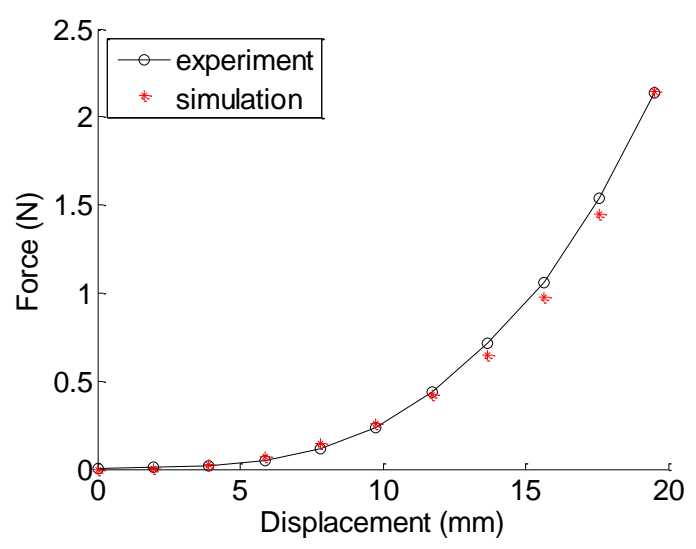

a)

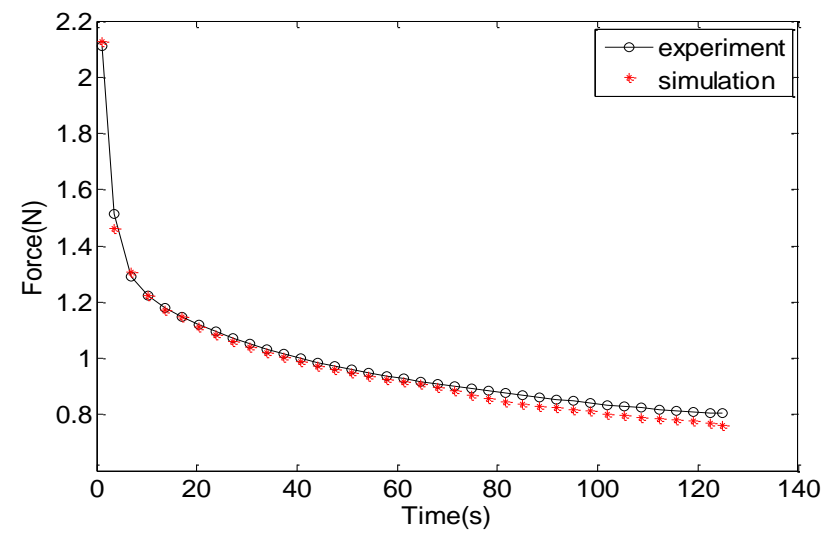

b)

Figure 10. The force-displacement (a) and force relaxation (b) responses of the bovine liver of Animal \#1 (solid circles) and the corresponding ones obtained from the FE simulations (red stars).

A Generalized Maxwell Solid (GMS) is used to model the viscoelastic behavior of the livers [21]. Then, the time-dependent relaxation modulus of the livers under ramp and hold strain input can be expressed analytically as

$$
E_{R}(t)=E_{0}\left[1-\sum_{j=1}^{N} \alpha_{j}\right]+E_{0} \sum_{j=1}^{N} \alpha_{j} e^{-t / \tau_{j}}
$$

where, $E_{0}$ is the short-term elastic modulus, $\alpha_{\mathrm{j}}$ is the relative modulus and $\tau_{j}$ is the time constant, and $\mathrm{N}$ is the number of terms (i.e. Maxwell arms) used in the GMS model. To be consistent with the experiments, an instantaneous displacement of $20 \mathrm{~mm}$ is applied to the FE model of each liver at the first time step of the simulations and then the probe is held there for the next 124 time steps (Fig. 9a) to estimate the optimum viscoelastic material coefficients through the inverse solution. The inverse solution is iterated until the total error between the experimental relaxation force and the simulated one is less than $0.05 \mathrm{~N}$ (Fig. 10b). In our case, $\mathrm{N}=2$ returns satisfactory results (Table 3 ). 
Following the estimation of the hyper-viscoelastic material properties of the livers, the insertion of the needles into the FE model of each liver is simulated in ANSYS (Fig 9b). In the FE model, besides the nodes at the base, the ones on the left boundary are also initially constrained to have zero displacement, but this constraint is released later as the needle penetrated into the mesh. To be consistent with the experiments, each neddle is inserted into the FE model to the depth of $20 \mathrm{~mm}$ with a rate of $3 \mathrm{~mm} / \mathrm{step}$. At each time step of our FE simulations, the total work done by the nodes at the contact interface is calculated using their displacement and the force acting on them. The fracture work, $\mathrm{W}_{\mathrm{f}}$, is calculated by multiplying the fracture toughness (Table 2) with the crack area. Then, the difference between the total work and the fracture work gives the viscoelastic work, $\mathrm{W}_{\mathrm{v}}$. When $\mathrm{W}_{\mathrm{f}}$ is exceeded $\mathrm{W}_{\mathrm{v}}$, the constraint on the node that is in contact with the needle is released, causing the separation of the node from the boundary and further penetration of the needle into the mesh (Fig. 11). 
PRE-PROCESSING

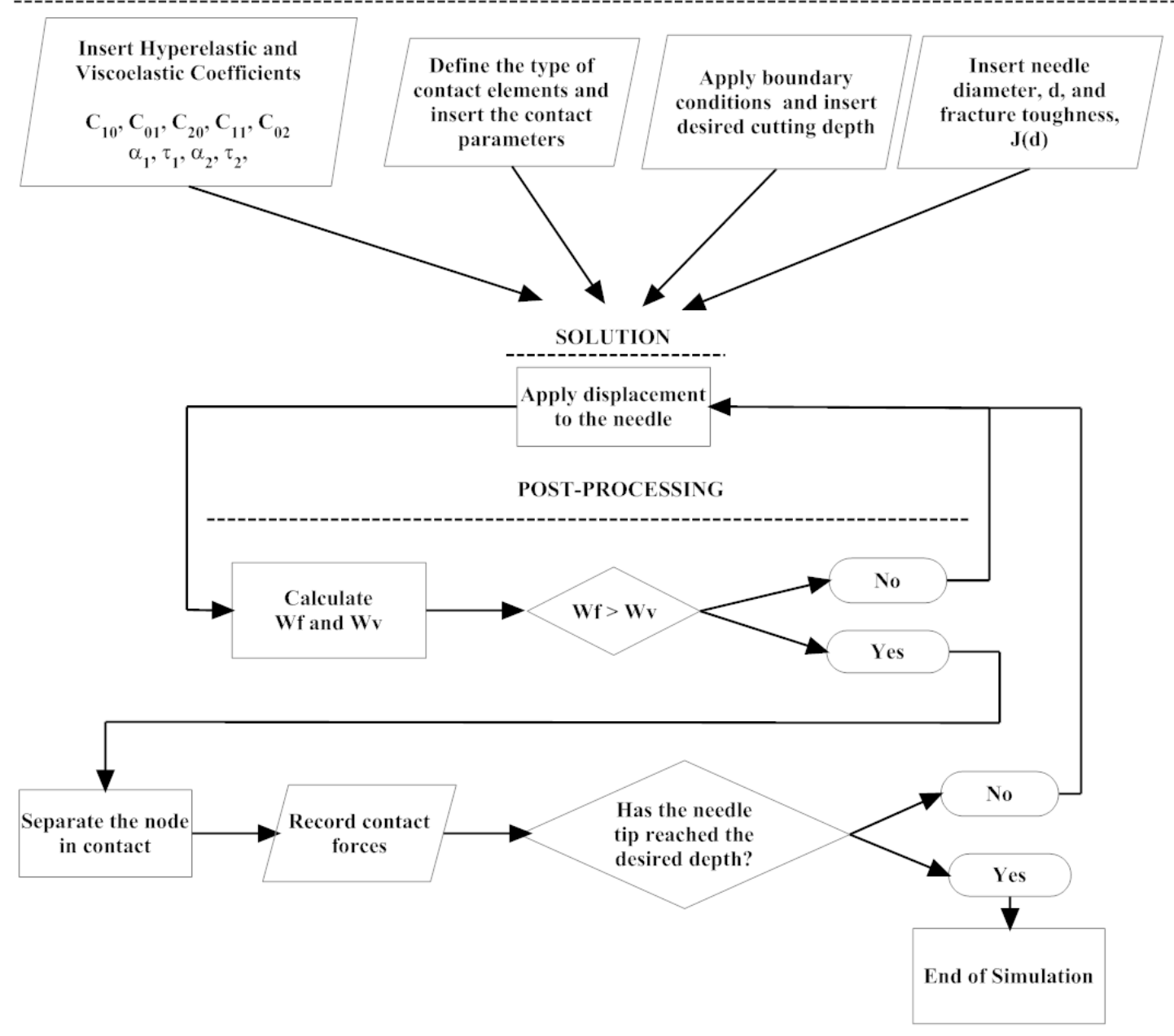

Figure 11. The flowchart of simulating needle insertion in ANSYS. 
The simulated force response is recorded as a function of the penetration depth to compare it with the experimental data (Fig. 12).

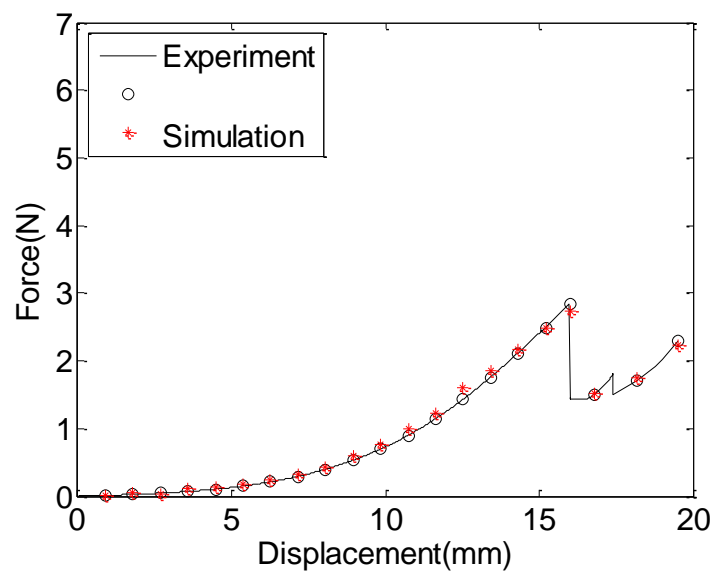

a

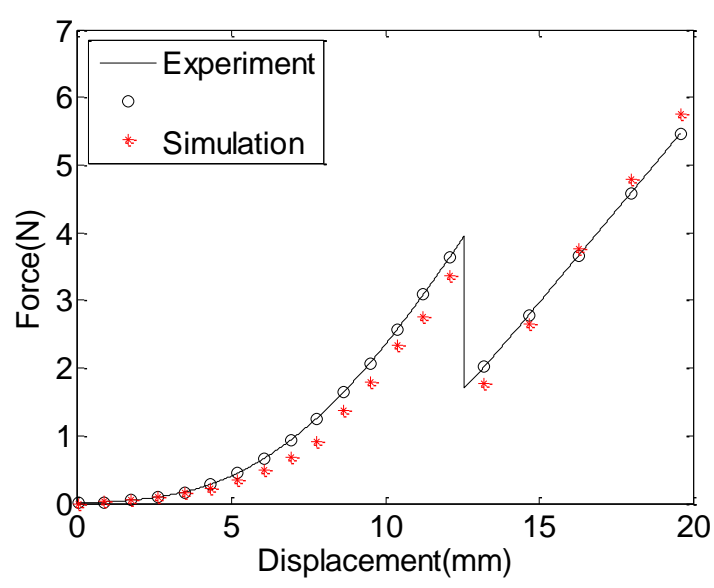

c

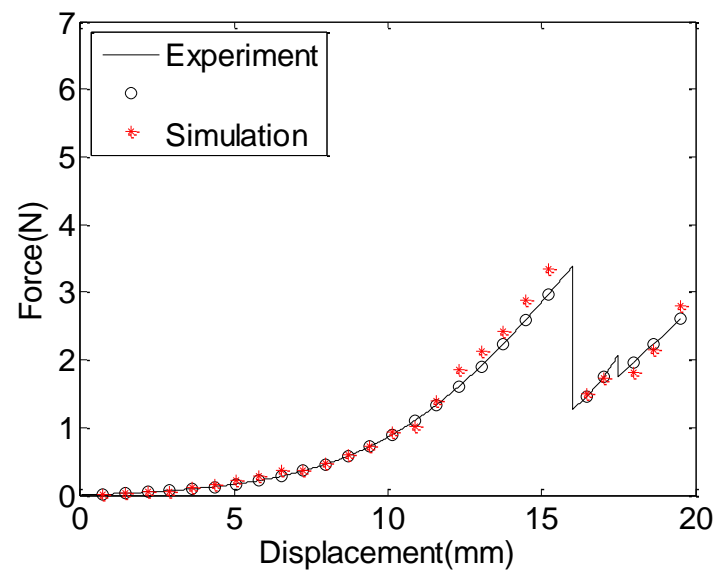

b

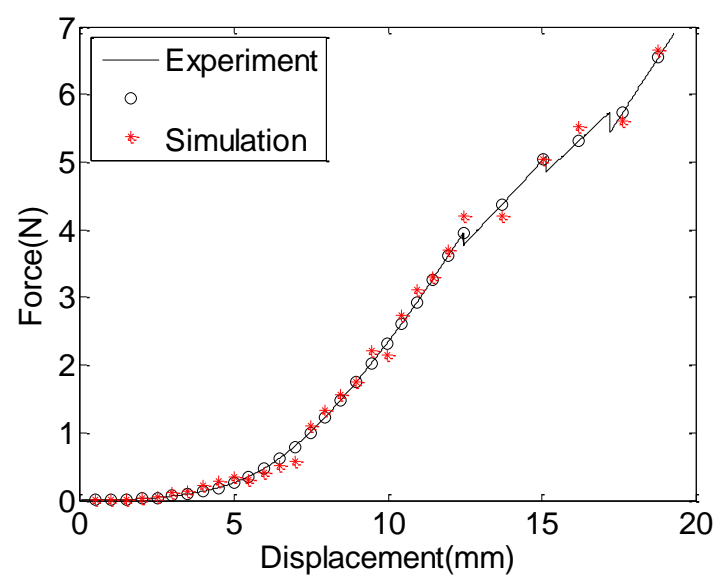

d

Figure 12. The experimental and the simulated force responses of the bovine liver of Animal \# 1 during the needle insertion for the needle diameters of (a) $2 \mathrm{~mm}$, (b) $3 \mathrm{~mm}$, (c) $4 \mathrm{~mm}$, and (d) $5 \mathrm{~mm}$.

\section{Discussion}

The results of the needle insertion experiments show that the fracture toughness is a linear function of needle diameter and a unique value can be estimated from the experimental data by curve fitting. Although the increase in force response as a function of needle diameter 
has been reported in [19] and different values of fracture toughness have been calculated for different needle diameters in [1], the relation between the needle diameter and fracture toughness has been overlooked in the literature. On the other hand, it is important to emphasize that the number of existing studies on fracture toughness of soft tissues is already very limited. Although the subjects and the methods used in some of those studies are different than ours, the fracture toughness values reported in all of them show large variations, which suggest that the effect of critical dimension of the cutting tool on the fracture toughness has been neglected in the analysis. Based on the experimental data collected from 3 animals, we estimated the fracture toughness of bovine liver as $164 \mathrm{~J} / \mathrm{m}^{2}$ with a standard deviation of 6 $\mathrm{J} / \mathrm{m}^{2}$. The mean value reported in our study for bovine liver is comparable to the ones reported for pig liver, the bounds of our toughness values are significantly tighter than the ones reported in earlier studies (varying between 75.8 and $185.6 \mathrm{~J} / \mathrm{m}^{2}$ in [1] and between 186.98 and $224.83 \mathrm{~J} / \mathrm{m}^{2}$ in [2]). The large variation reported in earlier studies could also be attributed to the differences in the material properties of the subjects being tested as well as the measurement methods and devices. For example, in our preliminary experiments performed with thin syringe needles having diameters less than $2 \mathrm{~mm}$, the collected data was noisy due to the buckling of the needles and it was not possible to identify the distinct phases of the insertion in most of the trials after the data was filtered. For this reason, we utilized custommade needles having diameters larger than a typical syringe needle in our current study to collect less noisy and more reliable data. In particular, due to the large diameters of the needles being employed, sudden drop in the force response after the puncture was more apparent in the recorded data.

In order to validate our experiments on bovine liver and support our hypothesis that the fracture toughness of a soft object depends on needle diameter, we have also conducted insertion experiments with a cylindrical silicone sample and investigated the 
effect of needle diameter on its fracture toughness (Fig. 13). As a side objective, the effect of insertion rate of the needle on the fracture toughness was also investigated.

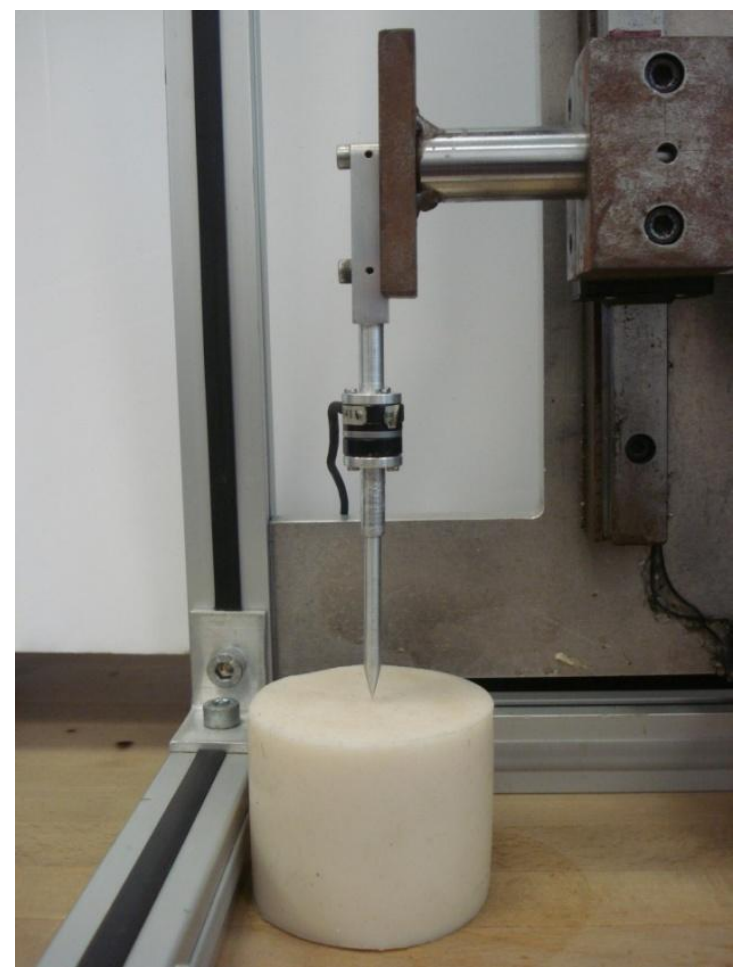

Figure 13. The cylindrical silicone sample used in our validation experiments

Table 4. The fracture toughness $\left(\mathrm{J} / \mathrm{m}^{2}\right)$ of the silicone sample for different needle diameters and insertion rates (note that each insertion experiment was repeated 4 times)

\begin{tabular}{|c|c|c|c|c|}
\hline $\begin{array}{l}\text { Diameter } \\
\text { Insertion } \\
\text { Rate }\end{array}$ & $2 \mathrm{~mm}$ & 3 mm & $4 \mathrm{~mm}$ & $5 \mathrm{~mm}$ \\
\hline $0.5 \mathrm{~mm} / \mathrm{s}$ & $146.18 \pm 4.54$ & $94.00 \pm 2.73$ & $59.00 \pm 2.99$ & $33.515 \pm 0.44$ \\
\hline $3 \mathrm{~mm} / \mathrm{s}$ & $144.60 \pm 3.25$ & $87.10 \pm 0.42$ & $50.75 \pm 0.212$ & $26.05 \pm 2.33$ \\
\hline $5 \mathrm{~mm} / \mathrm{s}$ & $140.80 \pm 2.46$ & $87.96 \pm 2.89$ & $48.88 \pm 2.27$ & $33.54 \pm 0.96$ \\
\hline Average & $143.44 \pm 4.06$ & $90.00 \pm 3.97$ & $52.90 \pm 5.35$ & $32.16 \pm 3.18$ \\
\hline
\end{tabular}

As in the case of bovine liver, there is a linear relation between the needle diameter and the fracture toughness estimated by the energy method (Fig. 14). The y-intercept of the fitted line $\left(y=-37 x+210, R^{2}=0.962\right)$ was used to estimate the fracture toughness of 
the silicone as $210 \mathrm{~J} / \mathrm{m}^{2}$. The results of this study also suggest that the effect of insertion rate on the fracture toughness of the silicon sample is not significant, at least for the insertion rates used in the experiments $(0.5 \mathrm{~mm} / \mathrm{s}, 3 \mathrm{~mm} / \mathrm{s}$, and $5 \mathrm{~mm} / \mathrm{s})$.

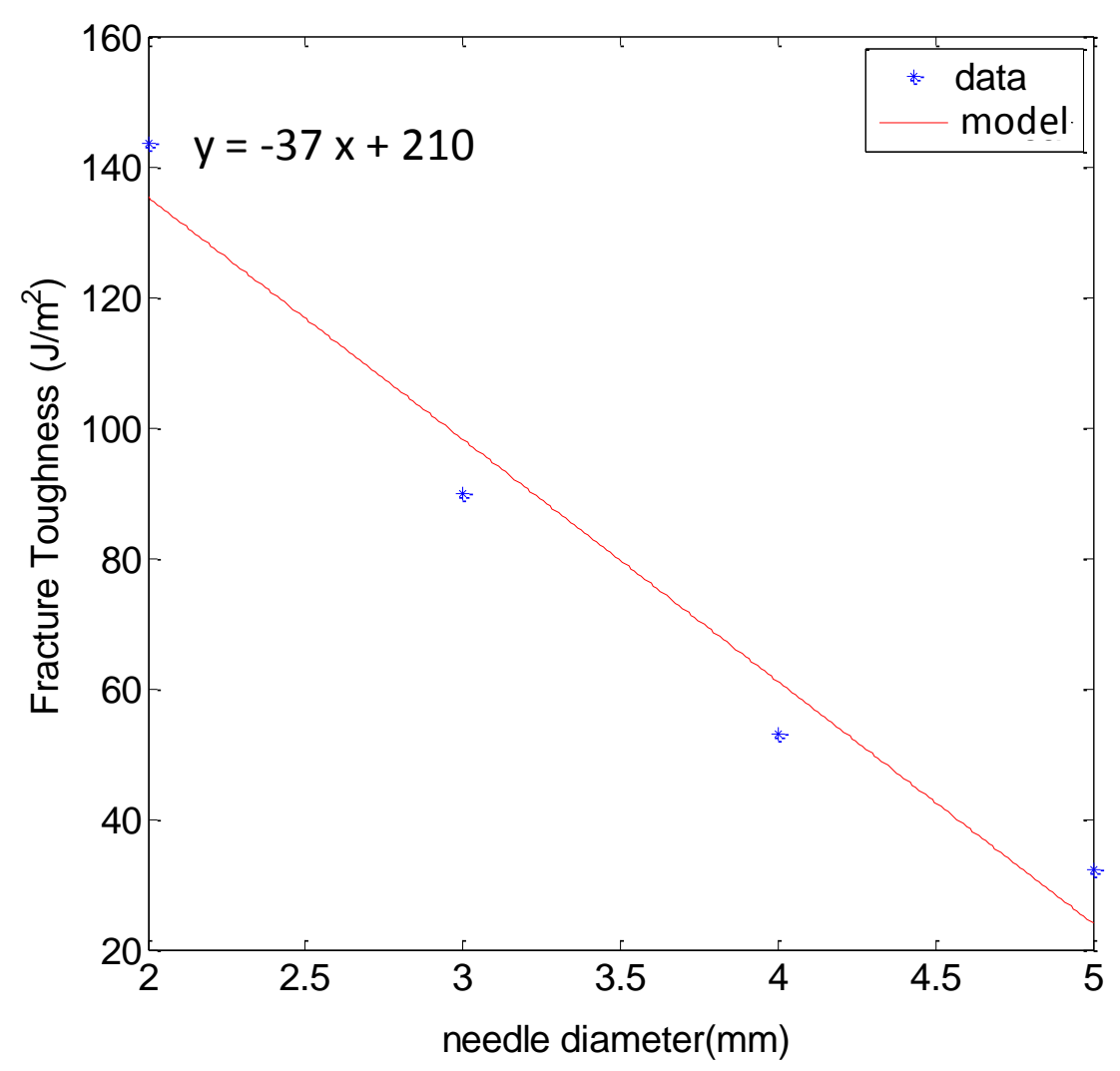

Figure 14. The fracture toughness of the silicone sample as a function of needle diameter.

In order to validate the experimental results on needle insertion, FE simulations were performed in this study. The force response obtained from the FE simulations for different needle diameters showed an excellent agreement with the ones obtained through the insertion experiments (Fig. 12). While the earlier studies have also utilized FE techniques to simulate needle insertion into soft tissue $[\mathbf{5}, 23, \mathbf{2 4}, \mathbf{2 5}]$, they mostly focused on modeling needle deformations rather than tissue deformations and relied on linear FE models of soft tissue. Misra et al. [5] and Nienhuys and van der Stappen [23] developed a hyperelastic FE model to simulate the needle insertion into soft tissue, but the viscoelastic effects have 
been neglected. Salcudean et al. [26] developed both linear and Neo-Hookean based hyperelastic FE models of a deformable prostate and its surrounding tissue in $3 D$ to simulate the needle insertion during prostate brachytherapy, but again viscoelastic effects have been neglected. Mahvash and Dupont [27] utilized a linear Maxwell solid with $\mathrm{N}=1$ to investigate the viscoelastic response of soft tissue during needle insertion. More importantly, most of the earlier studies have not integrated the material properties of a soft tissue measured experimentally into a FE model to validate the experimental data collected through the insertion experiments performed on the same tissue. Only, Kobayashi et al. [28] developed non-linear and viscoelastic FE models of soft tissue in $2 D$ to validate the results of their needle insertion experiments. Different insertion depths and velocities were simulated to show that the results of the simulations matched perfectly to that of the experiments when viscoelasticity and non-linearity were both included in the FE model. In this regard, our FE approach provides an "end-to-end" solution for the validation of the experimental data collected by the needle insertion experiments. We have made several modeling assumptions and simplifications to reduce the number of computations in our FE simulations. Although we collected data from whole livers in our experiments, we only considered the immediate area around the tool contact in our FE analysis. Furthermore, we have constructed our FE model from axisymmetric 2D elements to further reduce the number of computations. During the FE simulations, we observed that it was not possible to achieve a perfect, non-penetrating contact in ANSYS. The penetration is controlled by two parameters in ANSYS; FKN, which defines the contact stiffness, and FTOLN, which is the penetration tolerance. In our simulations, FKN was the key parameter affecting the accuracy and the convergence of the solutions. Higher values of FKN reduced the penetration between the two surfaces, but caused convergence problems. On the other hand, lower values reduced the convergence problems by maximizing the penetration, but the results were unreliable due to 
the distorted elements in the mesh. Both parameters (FKN and FTOLN) were set by trial and error such that there were no convergence and distortion problems.

\section{Conflict of interest statement}

There is no conflict of interest.

\section{Acknowledgements}

D. Canadinc acknowledges financial support by the Turkish Academy of Sciences (TUBA) within the Young Scientist Award Program (GEBIP).

\section{References}

1. Azar, T., Hayward, T., 2008. Estimation of the fracture toughness of soft tissue from needle insertion. Proc. 4th Int. Symp. Biomed. Simul. (ISBMS 2008), LNCS 5104, 166175.

2. Chanthasopeephan, T., Desai, J. P., Lau, A.C.W., 2006. Determining fracture characteristics in scalpel cutting of soft tissue. IEEE/RAS-EMBS Conference on Biomedical Robotics and Biomechatronics, 899-904.

3. Pereira, B. P., Lucas, P. W., Teoh, S.-H., 1997. Ranking the fracture toughness of thin mammalian soft tissues using the scissors cutting test. J. Biomech. 30, 91-94.

4. Comley, K., Fleck, N. A., 2010. The toughness of adipose tissue: measurements and physical basis. J. Biomech. 43, 1823-1826.

5. Misra, S., Reed, K.B., Douglas, A.S., Ramesh, K.T., Okamura, A.M., 2008. NeedleTissue Interaction Forces for Bevel-Tip Steerable Needles, Proc. of the $2^{\text {nd }}$ Biennal 
IEEE/RAS-EMBS Int. Conf. on Biomedical Robotics and Biomechatronics, Scottsdale, USA, October, 224-231.

6. Shergold, O.A., 2004. The Mechanics of Needle-free Injection, Department of Mechanical Engineering, Cambridge University: Cambridge, p. 200.

7. Shergold, O.A., Fleck, N.A., 2005. Experimental investigation into the deep penetration of soft solids by sharp and blunt punches, with application the the piercing of skin, $\mathrm{J}$. Biomech Eng, 127(5), 838-48.

8. Heverly, M., Dupont, P., 2005. Trajectory Optimization for Dynamic Needle Insertion. Proc. IEEE Int. Conf. On Robotics and Automation (ICRA), 1658-1663

9. Okamura, A.M., Simone, C., O'Leary, M.D., 2004. Force modeling for needle insertion into soft tissue. IEEE Trans. on Biomedical Engineering, 51 (10), 1707-1716.

10. Frick, T.B., Marucci, D.D., Cartmill, J.A., Martin, C.J., Walsh, W.R., 2001. Resistance forces acting on suture needles. J. Biomech 34, 1335-1340.

11. Okazawa, S., Ebrahimi, R., Chuang, J., Salcudean, S. E., Rohling, R., 2005. Hand-held steerable needle device, IEEE/ASME Transactions on Mechatronics, 10(3): 285-296.

12. DiMaio, S. P., Salcudean, S. E., 2005. Interactive simulation of needle insertion models. IEEE Transactions on Biomedical Engineering, 52(7): 1167-1179.

13. Chong, S.Y., Chong, L. A., Ariffin, H., 2010. Accurate prediction of the needle depth required for successful lumbar puncture. American Journal of Emergency Medicine, 28, 603-606.

14. Wang, X., Puram, S., 2004. The Toughness of cortical bone and its relationship with age. Annals of Biomedical Engineering 32 (1), 123-135.

15. Yan, J., Taskonak, B., Platta, J.A., Mecholsky, J. J., 2008. Evaluation of fracture toughness of human dentin using elastic-plastic fracture mechanics. J. Biomech. 41, $1253-1259$. 
16. Abolhassani, N., Moallem, M., 2007. Needle insertion into soft tissue: A survey. Medical Engineering \& Physics, 29(4), 413-431.

17. Atkins, A.G., Mai, Y.-W., 1985. Elastic and Plastic Fracture, Metals, Polymers, Ceramics, Composites, Biological Materials. Ellis Horwood Limited.

18. Shergold, O.A., Fleck, N.A, 2004. Mechanisms of deep penetration of soft solids, with application to the injection and wounding of skin, Proc. R. Soc. Lond. A, 460, 3037-3058

19. Okamura, A. M. Simone, C., O’Leary, M.D., 2004. Force modeling for needle insertion into soft tissue. IEEE Trans. Biomed. Eng. 51(10), 1707-1716.

20. Maurin, B. Barbé, Bayle, L. B., Zanne, P., Gangloff, de Mathelin, J., M., Gangi, A., Soler, L., Forgione, A. 2004. In vivo study of forces during needle insertions. Proc. of the Medical Robotics, Navigation and Visualization Scientific Workshop (MRNV), Remagen, Allemagne, March, 415-422.

21. Ocal, S., Ozcan, M.U., Basdogan, I., Basdogan, C., 2010. Effect of preservation period on the viscoelastic material properties of soft tissues with implications for liver transplantation. ASME J. Biomech. Eng., 132(10), 101007 (7 pages).

22. Samur, E., Sedef, M., Basdogan, C., Avtan, L., Duzgun, O., 2007. A robotic indenter for minimally invasive measurement and characterization of soft tissue behavior. Medical Image Analysis 11(4), 361-373.

23. Nienhuys, H-W., van der Stappen, F. A., 2004. A computational technique for interactive needle insertions in $3 \mathrm{~d}$ nonlinear material. Proc. IEEE Int. Conf. on Robotics and Automation (ICRA), 2061-2067.

24. Goksel, O., Dehghan, E., Salcudean, S.E., 2009, Modeling and simulation of flexible needles, Medical Engineering \& Physics, 31(9), 1069-1078. 
25. Hing, J. T., Brooks, A. D., Desai, J. P., 2006. Reality-based needle insertion simulation for haptic feedback in prostate brachytherapy. Proc. IEEE Int. Conf. on Robotics and Automation (ICRA), 619-624.

26. Dehghan, E., Salcudean, S. E., 2009. Needle insertion parameter optimization for brachytherapy, IEEE Trans. on Robotics, 25(2), 303-315.

27. Mahvash, M., Dupont, P.E., 2010. Mechanics of Dynamic Needle Insertion into a Biological Material, IEEE Trans. Biomed. Eng. 57(4), 934-943.

28. Y. Kobayashi, A. Onishi, H. Watanabe, T. Hoshi, K. Kawamura, and M. G. Fujie, 2008. Experimental validation of viscoelastic and nonlinear model of liver for needle insertion simulation. Proc. IEEE Int. Conf. Biomedical Robotics and Biomechatronics, 469-476. 